\title{
PADRÕES DE RELACIONAMENTOS ENTRE GRUPOS DE PESQUISA E O SETOR PRODU- TIVO NO BRASIL: UMA ANÁLISE POR ÁREA DE CONHECIMENTO
}

Lucas Teixeira Araújo

Resumo: O artigo tem como objetivo realizar uma análise da interação entre universidade e empresa no sistema nacional de inovação brasileiro pela ótica dos grupos de pesquisa separado em áreas do conhecimento. Foram criados indicadores que contemplam várias dimensões desse processo de interação, de forma a identificar similaridades e diferenças entre as áreas de pesquisa que revelam particularidades do sistema nacional de inovação brasileiro.

Palavras Chaves: Interação universidade/empresa, sistema de ciência e tecnologia, sistema nacional de inovação.

\begin{abstract}
This article aims to develop an analysis about universities-firms interaction in Brazilian national system of innovation from the view of academic research group, disaggregated in different in knowledge areas. Different indexes were crated comprising distinct dimensions of the interaction in order to identify similarities and differences among the research areas, which might particularities of the Brazilian national system of innovation.
\end{abstract}

Key words: Universities/firms interaction, National System of science and technology, National System of innovation.

Área de classificação de ABEIN: Área 6

Área de classificação do Journal of Economic Literature: O31, O32 e O33 


\section{Introdução}

O artigo aborda a temática da interação entre universidade e empresas a partir de uma perspectiva neo-schumpeteriana. Esse tema se torna importante à medida que os economistas buscam entender como se estruturam os fluxos de conhecimento que geram desenvolvimento econômico, concebidos como um elemento crítico característico dos sistemas nacionais de inovação. Os trabalhos na área intensificaram a partir do início da década de 1990 (Klevorick, 1995) pela constatação de que as universidades teriam particular importância no que diz à formação de capital humano. Cohen et. al (2002) desenvolvem uma metodologia que buscava identificar os padrões de interação e como a universidade contribuía em outros campos que não fossem a formação de capital humano. Schartinger et. al (2001) adota uma metodologia que utiliza elementos dos dois surveys americanos para um estudo aplicado à Áustria. Vários outros surveys semelhantes surgem com base nesses três primeiros trabalhos, destacando-se aplicações para a Holanda (Tijssen, 2006), para a Suíça (Arvanits, et. al 2006), para o México (Fuentes e Dutrénit, 2012), Argentina (Arza, 2010) e Brasil (Suzigan et. al, 2011).

$\mathrm{O}$ artigo tem como objetivo encontrar as diferenças e semelhanças entre os grupos de pesquisa de diferentes áreas do conhecimento. Esse tema é vistos como um elemento importante para a caracterização do grau de sofisticação de um sistema nacional de inovação e as áreas mais importantes no sistema nacional de ciência e tecnologia. O trabalho é desenvolvido em cinco seções, além dessa introdução. A segunda seção apresenta o referencial teórico que fundamenta a análise posterior. A terceira seção é dedicada à caracterização da base de dados e à descrição da metodologia utilizada. A quarta seção apresenta uma caracterização sintética dos grupos de pesquisa, por área de conhecimento. A quinta seção apresenta um esforço de caracterização do padrão de relacionamento entre grupos de pesquisa e o setor produtivo, por área de conhecimento. Uma última seção sumariza algumas considerações finais retiradas da análise e possíveis desdobramentos analíticos na exploração da temática.

\section{Referencial Teórico}

Freeman e Soete (2008) desenvolvem o conceito de sistema nacional de inovação a partir de uma perspectiva histórica, com base na teoria de List (1983). A Alemanha havia desenvolvido um sistema diferente do inglês no fim do século XIX, constituindo um forte sistema de treinamento e educação para a sua população, além de ter presenciado o surgimento dos grandes laboratórios de pesquisa das companhias, principalmente no setor químico. Essas especificidades germânicas fizeram com que o país superasse a Inglaterra em muitos indicadores econômicos já no final do século XIX. Outro país que se destacou no final do século XIX e tinha optado por uma estratégia peculiar foi os Estados Unidos. Esse baseou seu desenvolvimento na abundancia de recursos naturais além de uma maior concentração em atividades intensivas em capital e uma escala de produção maior que a bretã. Freeman e Soete (2008) comparam também as trajetórias dos japoneses com a União Soviética e dos países do Leste Asiáticos com os latinos americanos. Para os autores, tanto os Japoneses quanto aqueles do Leste Asiático se saíram melhores graças às suas mudanças institucionais que levaram ao desenvolvimento econômico.

Outro estudo fundamental é o de Nelson (1993), que caracteriza o sistema nacional de inovação como o conjunto das instituições que levariam ao desempenho inovativo das firmas de um determinado país. Nesse estudo, o autor edita um trabalho comparativo do desenvolvimento econômico de 13 países evidenciando a evolução institucional de cada um deles. O autor também faz uma introdução conceitual na qual busca uma definição concisa. Nessa abordagem, o agente mais importante seriam as firmas e os agentes secundários seriam as universidades e os institutos públicos de pesquisa e os governos. Esse grupo secundário daria apoio às firmas para que elas consigam uma posição de destaque e competitividade no mercado mundial. Lundvall (2005) vê essa definição como estreita e propõe um conceito mais abrangente. Entretanto, isso não tira o brilhantismo do trabalho de Nelson (1993), que nos possibilita encontrar as semelhanças e diferenças de cada sistema nacional de inovação.

Lundvall (2005) desenvolve uma abordagem particular do conceito de sistemas nacionais de inovação. Nessa visão, atribui mais atenção aos processos de interação e transmissão de conhecimento do que de fato à inovação das firmas. Esses processos passam a ter importância significativa para o desen- 
volvimento econômico de um país no que o autor chamou de economia do conhecimento Assim, os processos inovativos estariam fortemente correlacionados com a existência de relações entre as organizações inovadoras de fato, firmas, e as organizações difusoras de qualidades técnicas e científicas como universidades e institutos públicos de pesquisa (LUNDVALL, 1992). Os países teriam modos distintos de organizar essas interações, pois, se diferenciam por suas culturas, normas, leis e regras peculiares (JONHSON, 1992). Cooke et al., (1998) propõe uma divisão segundo a qual se deveria tratar como instituição apenas aquelas definidas na visão vebleniana e, governos, firmas e universidades e institutos de pesquisa deveriam ser entendidos como organizações. As instituições seriam as regras do jogo enquanto as organizações seriam os jogadores, sendo que essas duas partes coordenam as interações. (COOKE et al., 1998).

Os estudos de sistemas de inovação não se esgotam nessas análises e uma série de determinações secundárias aparece na literatura. Dentre essas, pode-se identificar aquelas referidas aos conceitos de sistemas regionais de inovação (COOKE et al., 1998), Sistemas nacionais de inovação imaturos (ALBUQUERQUE, 1999; BERNARDES E ALBUQUERQUE, 2003), sistemas setoriais de inovação (MALERBA, 2002), sistemas de cidades inovadoras (JOHNSON, 2008). Na análise desenvolvida a seguir, o conceito de sistema nacional de inovação imaturo será considerado. Albuquerque (1999) definiu essa estrutura da seguinte forma, com base no trabalho de Freeman e Soete (2008):

"They share with Latin American economies some characteristics described by Freeman (1995): the existence of science infrastructure (university research institutes, and governments agencies); weak commitment of business firms to innovative investments; presence of education skills, but with problems and serious flaws” (Albuquerque, 1999 p 37)

No trabalho de Bernardes e Albuquerque (2003), os autores constroem um modelo que relaciona o número de patentes ao número de artigos produzidos por um país com o intuito de definir um sistema imaturo. O resultado demonstra uma quebra estrutural que representa a diferença entre países maduros e imaturos, com o Brasil se localizando dentro dos países imaturos. Isso sugere que o conhecimento gerado no país é insuficiente para criar uma dinâmica inovadora. Essa característica pode ser relacionada com problemas históricos do nosso processo de industrialização no que diz respeito à absorção tecnológica (BERNARDES E ALBUQUERQUE, 2003). Nos países com um sistema nacional de inovação imaturo, o processo de interação universidade-empresa é debilitado pelo enfraquecimento das bases do sistema nacional de inovação, bem como em função do baixo nível de P\&D interno realizado pelas empresas (SUTZ, 2000). O trabalho de Arocena e Sutz (2003) diz que as particularidades dos sistemas nacionais de inovação dos países latino-americanos levariam a tipos de interação tradicionais e de pouca capacidade de trocas tecnológicas. Esse ponto, porém, é questionado nos trabalhos de Rapini (2007) e Suzigan et al., (2011) os quais percebem uma complexidade e riqueza bem maiores das interações brasileiras.

É a partir desse contexto que se reforça a relevância da temática referente à intensidade e amplitude da interação universidade-indústria como um elemento fundamental para a caracterização dos sistemas nacionais de inovação. A importância da contribuição do conhecimento científico para a viabilização de processos inovativos reforça o papel estratégico desempenhado pelas universidades e institutos de pesquisa, na medida em que os mesmos constituem uma fonte primordial de geração deste conhecimento. Estas instituições desempenham um papel crescentemente importante, seja como fonte de conhecimento geral ou específico, seja na formação de profissionais aptos ao envolvimento com atividades inovativas no setor empresarial. Apesar do argumento de que a comunidade acadêmica e o setor empresarial operam como instâncias de geração de conhecimentos que se movem segundo lógicas distintas, as quais se refletiriam nos respectivos quadros de referência e nos padrões de comportamento dos agentes inseridos em cada contexto, observa-se um movimento geral de aproximação entre estas instâncias com a consolidação de uma economia crescentemente "baseada no conhecimento" (LASTRES et al., 2002), na qual a esfera acadêmica constitui um importante agente motor do desenvolvimento, oferecendo um suporte fundamental à difusão do progresso técnico e à construção de capacitações produtivas e inovativas nos planos nacional e regional.

No âmbito de uma economia crescentemente “baseada no conhecimento”, é possível destacar uma dinâmica mais geral marcada por forças indutoras de um aprofundamento das interações entre o mundo acadêmico e a esfera industrial. Por um lado, este aprofundamento reflete mudanças que vêm se proces- 
sando no sistema de valores que orientam as ações de agentes inseridos na comunidade acadêmica, particularmente no sentido do fortalecimento de uma visão "mission oriented" (GIBBONS et al., 1994) responsável pela geração de incentivos à realização de investigações em linhas de P\&D associadas a oportunidades atrativas de aplicações técnico-econômicas. Por outro lado, também se observa uma tendência ao fortalecimento do caráter interdisciplinar do conhecimento, não apenas no tocante a disciplinas estritamente científicas, como também no plano mais diretamente material das disciplinas de base tecnológica. Como consequência desses processos, verifica-se a consolidação de arranjos institucionais integrando as duas instâncias, a partir dos quais estrutura-se um sistema de incentivos adequado ao aprofundamento da interação, os quais assumem múltiplos formatos, tais como joint-ventures, incubadoras de empresas, parques tecnológicos, consórcios de $\mathrm{P} \& \mathrm{D}$, centros de transferência de tecnologia, centros de pesquisa cooperativa, instituições-ponte dedicadas ao gerenciamento de contratos de pesquisa, spin-offs de empresas de base tecnológica e alianças informais entre indústria, governo e universidades.

A interação universidade e empresas têm sido enfatizadas por uma vasta literatura no campo da economia da inovação, a qual ressalta a importância dos circuitos de retroalimentação positiva entre essas duas dimensões, característico dos sistemas de inovação consolidados dos países desenvolvidos. Nestes sistemas, é comum que as universidades e institutos de pesquisa produzam conhecimentos absorvidos por empresas e pelo setor produtivo, conforme comprovam estudos realizados por Klevorick et al., (1995), Narin et al., (1997), Cohen et al., (2002). Por outro lado, as empresas acumulam conhecimento tecnológico que fornece questões para a elaboração científica, conforme descrito por Rosenberg (1982). Como reflexo desse processo, consolidam-se fluxos virtuosos bidirecionais entre essas instâncias, discutidos nas análises de Brascomb et al., (1999) e de Mowery et al., (2004).

A partir dos diversos trabalhos realizados nessa linha, é possível destacar algumas conclusões importantes. Em especial, é observa-se algumas características das universidades envolvidas nas interações. Os grupos de pesquisa usualmente se beneficiam pela aquisição de recursos financeiros; na criação de novas oportunidades tecnológicas; e na publicação de artigos (PERKMANN e WALSH, 2009). Além disso, notam-se alguns resultados no que diz as características dos pesquisadores. Aqueles que pertencem a institutos públicos de pesquisas têm mais probabilidade de estarem interagindo com empresas que aqueles empregados em universidades (BOARDMAN e PONOMARIOV, 2009). Fatores como gênero, a idade e a experiência também exercem influência nas relações com empresas (BEKKERS e BODASFREITAS, 2008). Sendo que homens interagem mais, a experiência, contada por frequência de interações, também atua de forma positiva e a idade atua como uma espécie de 'U' invertido. A disponibilidade de recursos oferecida ao pesquisador pelo seu departamento e a qualidade das pesquisas concluídas também são fatores que afetam as interações (SCHARTINGER et al., 2002). Por fim, nota-se que a interação pode gerar custos indesejados, mas pode também gerar resultados vantajosos para as universidades. (CUMMINGS e KIESLER, 2007).

Suzigan e Albuquerque (2009) e Rapini (2007) identificam, com base na literatura especializada, algumas funções fundamentais da universidade: (1) Formação de pessoal em geral; (2) Formação de pessoal capacitado para fundar novas empresas, especialmente em novas áreas tecnológicas ("spin-offs"); (3) Fonte de conhecimento de caráter mais geral necessários para as atividades de pesquisa básica e fonte de conhecimento especializado relacionado à área tecnológica da firma; (4) Geração de conhecimento na forma de "spillovers" (utilizados por empresas e outros agentes com capacidade de absorção previamente construída); (5) Estabelecimento de interação com firmas estabelecidas, favorecendo processos inovativos; (6) Estabelecimento de canal para absorção de conhecimento gerado nos centros mais avançados. No âmbito específico dos países em desenvolvimento, destaca-se o papel da ciência na contribuição para o processo de catching-up, na medida em que a infraestrutura científica atua como um "instrumento de focalização" e como uma "antena” para identificar oportunidades tecnológicas, permitindo vincular o país aos fluxos científicos e tecnológicos internacionais, apoiando o seu desenvolvimento industrial e atuando como fonte para soluções criativas que dificilmente seriam obtidas fora do país (como, por exemplo, no caso de vacinas contra doenças tropicais).

Quanto às firmas, observa-se que elas estão interessadas em identificar mão de obra potencial além de capacitações científicas que podem ser utilizadas como aplicações para o mercado (ARVANITIS, et al., 2006). Vários trabalhos buscaram encontrar características das firmas que fazem aumentar as inte- 
rações, como, o tamanho (PÓVOA e MONSUETO 2011), se a firma é parte de uma grande corporação (FUENTES e DUTRÉNIT, 2012), o setor em que elas se encontram (BRITTO e OLIVEIRA, 2011; TIJSSEN, 2006), a intensidade tecnológica (PINHO, 2011) e o fato de uma empresa ser nacional ou multinacional (SILVA NETTO et al., 2011). Existem ainda estudos que observam se a proximidade geográfica influencia na interação das firmas com os grupos de pesquisa (COSTA et al., 2011; GARCIA et al., 2011).

Quanto à transmissão de conhecimento, pode-se ver que tanto trabalhos iniciais (KLEVORICK, et al., 1994) quanto os atuais (BEKKERS e BODAS-FREITAS; 2008) colocam a mobilidade de recursos humanos entre universidades e firmas como uma das formas mais importantes. A publicação de resultados de P\&D por artigos acadêmicos também é uma forte fonte de transmissão de tecnologia, porém, menos comum, dado que as firmas especificam tais termos em contratos (PERKMANN e WALSH, 2009). É possível observar no trabalho de Fuentes e Dutrénit (2012) que os canais de interação são separados em certos grupos, dependendo do grau de formalização, do grau de interação, da direção dos fluxos de conhecimento, e da natureza dos resultados aplicados.

No caso latino americano, em função do baixo nível de P\&D interno realizado pelas empresas locais Arocena e Sutz (2003) encontram evidências de que as articulações universidade-empresa no continente tendem a ficar circunscritas à prestação de serviços rotineiros e a atividades de consultoria técnica, raramente envolvendo atividades de pesquisa de caráter mais experimental. Entretanto, Rapini (2007) e Rapini et al., (2013) observam na região uma mudança de postura das universidades e instituições de pesquisa, principalmente no caso brasileiro, no sentido de acelerar investigações orientadas para busca de avanços que tenham uma maior relevância para a sociedade com pesquisas mais densas e que possibilitem uma comercialização efetiva dos resultados gerados.

Num contexto de sistema nacional de inovação imaturo o Brasil teria um grande número de instituições de pesquisa e ensino, porém não consegue constituir uma pesquisa densa e gerar a quantidade de engenheiros suficientes para tal atividade (SUZIGAN e ALBUQUERQUE, 2008). Pode-se perceber ainda que as universidades são utilizadas como o próprio departamento de P\&D das empresas (FRANCO et al., 2010) e que as interações assumem um caráter contingencial e descontínuo (RAPINI, 2007). Entretanto, o país é conhecido historicamente por gerar progressos científicos relevantes a partir da pesquisa pública em determinadas áreas. Dentre esses campos é possível destacar a aeronáutica, imunologia, agropecuária, mineração e geociências (SUZIGAN e ALBUQUERQUE, 2008).

Segundo análises anteriores dos sistemas de inovação (RAPINI, 2004; SILVA, 2003; BERNARDES e ALBUQUERQUE, 2003) há indícios de que, dado o estágio de desenvolvimento do país e o estágio ainda imaturo de construção do sistema nacional de inovação, as conexões estabelecidas entre a dimensão científica e a dimensão tecnológica são apenas parciais. Desse modo, fluxos bidirecionais e mutuamente dinâmicos parecem estar limitados a alguns setores e a campos específicos do conhecimento. Além disso, há também indícios de que, em vários campos, prevalecem fluxos unidirecionais originados principalmente das universidades em função da maior participação relativa do Brasil na produção científica mundial vis-à-vis a sua participação na produção tecnológica (ALBUQUERQUE, 1999). Por outro lado, face às evidências que apontam para o caráter limitado dessas interações no caso brasileiro (RAPINI, 2004; SILVA, 2003; BERNARDES e ALBUQUERQUE, 2003; RAPINI et al., 2013), torna-se particularmente importante quais as especificidades deste padrão de interação em diferentes campos do conhecimento.

\section{Base de dados e Metodologia}

\subsection{Descrição da base de dados e indicadores}

O artigo discute a interação univerisidade-empresa a partir de um recorte por diferentes campos do conhecimento. A base de dados utilizada integra a pesquisa denominada "A program of study of the processes involved in technological and economic catch up” organizada pelo professor Richard Nelson da Universidade de Columbia (SUZIGAN et al., 2011). Tal pesquisa consiste em duas modalidades de questionários direcionadas para as empresas e universidade e instituto de pesquisa cada uma. Os dados foram 
coletados entre 2007 e 2010.

Na análise realizada foi utilizado apenas o questionário aplicado a universidades e instituições de pesquisa. Participaram desse estudo todos os grupos de pesquisa que disseram ter algum tipo de interação com empresas no Censo de Grupos de Pesquisa de 2004. As informações acerca das interações e cooperações entre as universidades e as empresas são do ano de 2009 e o questionário busca compreender e avaliar todo o processo de interação entre os agentes em questão. A estratégia de captação de resposta foi realizada por correio eletrônico, acompanhamento telefônico ou acompanhamento presencial. No total foram contatados 2.151 grupos de pesquisa e obteve-se 1.005 respostas, o que gerou uma taxa de 46,7\%. Depois de uma limpeza para os dados que aqui serão trabalhados restaram 889 grupos, o que dá uma taxa de representatividade de $41,3 \%$ do universo. Entretanto, considerando apenas os grupos das grandes áreas do conhecimento pré-selecionadas tem uma participação de $47,26 \%$ do total ${ }^{1}$. A distribuição também se apresentou satisfatória para todas as áreas do conhecimento. Os grupos de engenharia biomédica foram totalmente cobertos pela pesquisa, seguido por genética $(69,23 \%)$ e odontologia $(62,50 \%)$. Por outro lado, as ciências com menor representatividade foram saúde coletiva (38,71\%), medicina (39,29\%) e outras áreas de saúde $(41,27 \%)$

A base de dados contém uma série de informações tais como tamanho do grupo de pesquisa, localização geográfica, universidade ou instituto ao qual pertence o grupo, escolaridade dos membros do grupo dentre outras. Nesse trabalho serão utilizadas as respostas das questões 1, 2, 3 e 5 da seção II, que contempla algumas características da interação de grupos de pesquisa com empresas. Essas questões buscam levantar informações sobre os tipos de relacionamento, os principais resultados, os benefícios ${ }^{2}$ da relação e os canais de informação para transferência de conhecimento respectivamente. As questões são compostas de uma série de itens nos quais o entrevistado deve dizer se cada característica é sem importância (1), pouco importante (2) moderadamente importante (3) e muito importante (4). Para tornar os dados mais operacionalizáveis fora criados alguns indicadores que serão descritos no QUADRO 1:

\section{QUADRO 1 - Estrutura de Indicadores considerados}

\begin{tabular}{|c|c|c|}
\hline Questão & Indicador & Item \\
\hline \multirow[t]{2}{*}{$\begin{array}{l}\text { Questão 1: Tipos de relacionamento } \\
\text { (Dimensão 1) }\end{array}$} & 1. Prestação de serviços & $\begin{array}{l}\text { 1. Testes para padronização /atividades de certificação da qualidade } \\
\text { 2. Avaliações técnicas, estudos de viabilidade, gerenciamento de projetos } \\
\text { 3. Serviços de engenharia } \\
\text { 4. Consultoria } \\
\text { 5. Treinamento e cursos } \\
\text { 6. Intercâmbio nas empresas }\end{array}$ \\
\hline & 2. $\mathrm{P} \& \mathrm{D}$ & $\begin{array}{l}\text { 7. Transferência de tecnologia (licenciamento) } \\
\text { 8. Projetos de P\&D em colaboração } \neg \neg\urcorner \text { com a empresa, com resultados de uso imediato } \\
\text { 9. Projetos de P\&D em colaboração com empresas, sem resultados de } \neg 7\urcorner \text { uso imediato } \\
\text { 10. Projetos de P\&D complementares às atividades de inovação da empresa } \\
\text { 11. Projetos de P\&D substitutos às atividades de inovação da empresa }\end{array}$ \\
\hline \multirow{3}{*}{$\begin{array}{l}\text { Questão 2: Principais resultados } \\
\text { (Dimensão 2) }\end{array}$} & 3. Reforço da Base científica & $\begin{array}{l}\text { 1. Novas descobertas científicas } \\
\text { 2. Novos projetos de pesquisa }\end{array}$ \\
\hline & 4. Inovação & $\begin{array}{l}\text { 3. Novos produtos e artefatos } \\
\text { 4. Novos processos industriais } \\
\text { 5. Melhoria de produtos industriais } \\
\text { 9. Patentes } \\
\text { 10. Software } \\
\text { 11. Design } \\
\text { 12. Criação de novas empresas (spin-offs) }\end{array}$ \\
\hline & 5. Formação acadêmica & $\begin{array}{l}\text { 6. Formação de RH e estudantes } \\
\text { 7. Teses e dissertações } \\
\text { 8. Publicações }\end{array}$ \\
\hline \multirow{3}{*}{$\begin{array}{l}\text { Questão 3: Benefícios } \\
\text { (Dimensão 3) }\end{array}$} & 6. Informação/conhecimento & $\begin{array}{l}\text { 1. Idéias para novos projetos de cooperação } \\
\text { 2. Novos projetos de pesquisa } \\
\text { 3. Intercâmbio de conhecimentos ou informações }\end{array}$ \\
\hline & 7. Desenvolvimento de recursos & $\begin{array}{l}\text { 4. Equipamentos/ instrumentos de uso compartilhado } \\
\text { 5. Recebimento insumos para as pesquisas } \\
6 \text {. Recursos financeiros }\end{array}$ \\
\hline & 8. Reputação e Networking & $\begin{array}{l}\text { 7. Novas redes de relacionamento } \\
\text { 8. Reputação }\end{array}$ \\
\hline
\end{tabular}

Fonte: Elaboração própria a partir do questionário aplicado a grupos de pesquisa no Survey Brasil

Os entrevistados responderam cada item acima com os valores 1, 2, 3, e 4. Para que cada resposta

\footnotetext{
${ }^{1} \mathrm{O}$ trabalho não considerou as áreas de ciências humanas, ciências humanas aplicadas, e linguística.

${ }^{2}$ Como demonstrado em Rapini et all (2013) a diferença entre resultados e benefícios se dá pela característica tangível do primeiro em relação à característica intangível do segundo.
} 
variassem entre 0 a 1 os valores acima foram transformados em $0,0.3,0.6,1$, respectivamente. Para a questão 1 foi criado dois indicadores. O primeiro é resultado da agregação entre os itens 1 e 6 da questão e recebeu o nome de "prestação de serviços". Os itens 7 a 11 foram agregados como "pesquisa e desenvolvimento (P\&D)”. Mais três indicadores foram criados na questão 2. Os itens 1 e 2 são responsáveis por um indicador de "base científica". Os itens 3 a 6 e 10 a 13 montam um indicador específico de "inovação". Os itens 7 a 9 formam um indicador de "formação acadêmica". Na pergunta 3, mais três indicadores foram criados. Quanto aos Benefícios, os itens 1 a 3 foram classificados como "informação/conhecimento". Os itens 4 a 6 como "desenvolvimento de recursos" e os itens 7 e 8 como reforço da “reputação e networking”.

\subsection{Descrição do método}

O artigo utilizará três métodos quantitativos de tratamento com base nos dados discutidos na subseção acima. O primeiro desses será a análise histogramas (SARTORIS, 2003). Essa possibilita a observação da distribuição dos dados em seus respectivos decis. O software utilizado para esse exercício foi o STATA 12. A análise será separada por cada uma das 4 dimensões mencionadas acima. Cabe ainda ressaltar que nessa etapa os dados não serão separados por áreas do conhecimento, sendo tratados para a base de dados como um todo.

O segundo método assim como o terceiro, buscarão as dissimilaridades dentre as áreas do conhecimento dadas pela TABELA 1. Sendo assim, será formulada uma medida de importância absoluta que será chamada de taxa de importância absoluta. Essa é representada pelo cálculo do percentual dos grupos de pesquisa que deram notas acima de 0,6 para cada indicador em cada uma das áreas de conhecimento. Essa medida desconsidera a variabilidade dos dados tanto no grupo escolhido (maior que 0,6) quanto no grupo preterido (menor que 0,6). Porém, ela capta o percentual de indivíduos concentrados em determinada faixa de distribuição dos dados, o que é interessante para notar o impacto de determinado indicador para as observações. O valor de 0,6 é escolhido porque o grupo que atrubuiu essa medida classifica o indicador como pelo menos importante. O método foi utilizado em alguns trabalhos nessa literatura como o de Cohen et. all (2002) e Rapini et. all (2013).

Por fim, no terceiro método será realizada uma razão das médias dos indicadores calculados para os grupos de pesquisas de determinada área do conhecimento (score da área de conhecimento) sobre a média geral do indicador (score do indicador). Isso pode ser expresso pela seguinte fórmula:

Em que:

$$
\operatorname{Ir}=\frac{\mu_{i j}}{\mu_{i}}
$$

Ir representa o índice de importância relativa;

$\mu_{i j}$ o score do indicador i para a área do conhecimento j; e

$\mu_{i}$ o score do indicador i.

O objetivo de tal procedimento é observar quão distante as respostas dos pesquisadores de uma determinada área do conhecimento se diferencia da média brasileira. O indicador poderá assumir três valores diferentes, caso seja igual a 1 significa que as duas médias são iguais e a área do conhecimento apresenta o mesmo indicador para a o total da base. Se o valor for menor que 1 o valor do indicador é menor que o da média e isso representa que os pesquisadores da determinada área dão uma importância menor que a geral. Se o valor for maior que 1 terá o caso contrário, ou seja, os grupos de tal área dão um valor maior que aquele encontrado para a média. Por essas características, esse procedimento será chamado de índice de desvio da média.

Esses métodos serão aplicados na seção seguinte do trabalho, que, anteriormente contará com uma breve apresentação das características gerais dos grupos de pesquisa.

\section{Análise dos resultados}




\subsection{Dados dos grupos de pesquisas}

Os grupos de pesquisa foram divididos de acordo com suas áreas de pesquisa declarada pelos seus pesquisadores chefes. A TABELA 1 sumariza algumas informações como o número de grupos, o número médio de pesquisadores, o número médio de pesquisadores com doutorado, o número de projetos financiados por instituições nacionais e por instituições internacionais e o percentual de grupos com pedido/concessão de patentes em cada uma das áreas.

Para que os dados se tornassem operacionalizáveis, algumas agregações tiveram que ser feitas. Sendo assim, os grupos recursos pesqueiros e engenharia de pesca, recursos florestais e engenharia florestal e morfologia ${ }^{3}$ foram reunidos em uma classe denominada recursos ambientais e engenharias afins. Os grupos de biologia geral, botânica e zoologia foram agrupados em apenas um campo. A ciência denominada saúde relacionada à bioquímica compreende os grupos de bioquímica, microbiologia, parasitologia, imunobiologia e biofísica. Já o conjunto das outras áreas da saúde engloba enfermagem, educação física, fisioterapia e terapia ocupacional, nutrição, fisiologia e fonoaudiologia. Foram adicionados à ciência da computação os grupos de matemática e probabilidade. Os campos de engenharia também tiveram que sofrer algumas alterações como a adição dos grupos de engenharia de minas nas engenharias de materiais e metalúrgica. As engenharias aeroespacial e naval foram alocadas juntamente com a engenharia mecânica. A engenharia civil recebeu os grupos de engenharia de transporte.

Nota-se que os grupos que têm o maior número de pesquisadores, em média, são das áreas de agronomia, farmácia e farmacologia e genética. Esse resultado enfatiza a tradição brasileira nesses campos que foram historicamente apoiados pelo poder público com a constituição de institutos públicos de pesquisa. Dentre esses destaca na agronomia a EMBRAPA e a EMATER em escala nacional além de institutos de abrangência estadual como o IAC em São Paulo, a EPAMIG em Minas Gerais e a EPAGRI em Santa Catarina. Em farmácia e farmacologia e genética há grandes investimento e desenvolvimento de capacitações por parte do Instituto Oswaldo Cruz e do Instituto do Butantã. Essa última ciência ainda conta com uma pesquisa histórica na ESALQ em Piracicaba (SCHWARTZMAN, 1979). Os grupos de medicina, saúde coletiva e biologia geral, botânica e zoologia são aqueles que têm as menores médias de pesquisadores.

Quanto ao número de pesquisadores com doutorado as áreas de destaque são agronomia, zootecnia, recursos ambientais e engenharias afins e ciência e tecnologia de alimentos. As ciências com menor número de doutores são das áreas de medicina, engenharia sanitária, física. O dado referente ao número de doutores bruto é pouco conclusivo, pois grupos com menos pesquisadores tendem a ter menos doutores. Assim, faz-se necessário observar o percentual de doutores perante o total dos pesquisadores. Esse dado está na quarta coluna da TABELA 1. Os grupos com mais de $60 \%$ de seus membros com doutorado são engenharia nuclear, medicina e recursos ambientais e engenharias afins. Isso pode ser explicado pela especificidade e raridade do capital humano necessário nessas áreas do conhecimento. Com os menores percentuais têm-se as áreas de saúde coletiva, genética, engenharia sanitária, engenharia mecânica, naval e aeroespacial, química, engenharia de materiais, metalúrgica e minas, outras áreas da saúde e ciência da computação, matemática e probabilidade.

Tabela1- Dados gerais dos grupos de pesquisa agregado por área do conhecimento

\footnotetext{
${ }^{3}$ Os grupos de morfologia da base estão relacionados com morfologia de peixes, dessa forma, faz sentido agrupá-los com as outras ciências da classe.
} 


\begin{tabular}{|c|c|c|c|c|c|c|c|}
\hline Área do conhecimento & $\begin{array}{l}\text { Número de } \\
\text { pesquisador } \\
\text { es }\end{array}$ & \begin{tabular}{|l|}
$\begin{array}{l}\text { Númenro de } \\
\text { pesquisadores } \\
\text { doutores }\end{array}$ \\
\end{tabular} & $\begin{array}{l}\% \text { de } \\
\text { doutores }\end{array}$ & $\begin{array}{l}\text { Projetos financiados } \\
\text { por instituições } \\
\text { nacionais }\end{array}$ & \begin{tabular}{|l|} 
Projetos financiados \\
por instituições \\
internacionais
\end{tabular} & $\begin{array}{l}\% \text { de grupos com } \\
\text { pedidos e/ou patentes } \\
\text { concendidas }\end{array}$ & $\begin{array}{l}\text { Número de } \\
\text { grupos por } \\
\text { área }\end{array}$ \\
\hline Agronomia & $\begin{array}{r}14,22 \\
\end{array}$ & $\begin{array}{r}, 89 \\
\end{array}$ & $56 \%$ & 3,48 & $\begin{array}{r}0,21 \\
\end{array}$ & $15 \%$ & 85 \\
\hline $\begin{array}{l}\text { Engenharia de Materiais, Metalúrgica } \\
\text { e Minas }\end{array}$ & 9,50 & 3,66 & $38 \%$ & 6,33 & 0,38 & $47 \%$ & 64 \\
\hline Engenharia Elétrica & 9,39 & 3,65 & $39 \%$ & 5,16 & 0,18 & $29 \%$ & 62 \\
\hline $\begin{array}{l}\text { Engenharia Mecânica, aeroespacial e } \\
\text { naval }\end{array}$ & 12,17 & 4,28 & $35 \%$ & 6,60 & 0,43 & $38 \%$ & 53 \\
\hline $\begin{array}{l}\text { Ciência da Computação, matemática } \\
\text { e probabilidade }\end{array}$ & 9,94 & 3,86 & $39 \%$ & 4,28 & 0,41 & $12 \%$ & 50 \\
\hline Engenharia Civil & 9,54 & 3,92 & $41 \%$ & 2,98 & 0,25 & $17 \%$ & 48 \\
\hline Química & 9,63 & 3,63 & $38 \%$ & 5,63 & 0,18 & $55 \%$ & 40 \\
\hline Geociências & 8,83 & 4,33 & $49 \%$ & 3,83 & 0,39 & $3 \%$ & 36 \\
\hline Saúdes relacionadas à bioquímica & 9,19 & 4,42 & $48 \%$ & 7,17 & 0,44 & $47 \%$ & 36 \\
\hline Medicina & 4,03 & 2,50 & $62 \%$ & 9,28 & 0,63 & $25 \%$ & 32 \\
\hline $\begin{array}{l}\text { Recursos ambientais e engenharias } \\
\text { afins }\end{array}$ & 10,00 & 6,26 & $63 \%$ & 5,26 & 0,23 & $6 \%$ & 31 \\
\hline Engenharia Química & 8,80 & 4,43 & $50 \%$ & 6,85 & 0,70 & $59 \%$ & 29 \\
\hline Outras áreas de saúde & 12,69 & 4,83 & $38 \%$ & 3,52 & 1,00 & $10 \%$ & 29 \\
\hline Engenharia de Produção & 7,35 & 3,46 & $47 \%$ & 1,31 & 0,04 & $23 \%$ & 26 \\
\hline Biologia Geral; Botânica e Zoologia & 6,48 & 3,56 & $55 \%$ & 2,92 & 0,24 & $12 \%$ & 25 \\
\hline Ciência e Tecnologia de Alimentos & 12,88 & 6,08 & $47 \%$ & 3,84 & 0,56 & $44 \%$ & 25 \\
\hline Medicina Veterinária & 8,91 & 3,66 & $41 \%$ & 2,54 & 0,13 & $13 \%$ & 24 \\
\hline Ecologia & 12,35 & 5,34 & $43 \%$ & 4,48 & 0,51 & $30 \%$ & 22 \\
\hline Farmácia e Farmacologia & 14,27 & 5,00 & $35 \%$ & 4,45 & 0,18 & $59 \%$ & 22 \\
\hline Zootecnia & 14,18 & 7,77 & $55 \%$ & 6,41 & 1,36 & $5 \%$ & 22 \\
\hline Engenharia Sanitária & 8,74 & 2,89 & $33 \%$ & 4,47 & 0,21 & $21 \%$ & 19 \\
\hline Física & 10,06 & 2,89 & $29 \%$ & 4,17 & 0,39 & $67 \%$ & 18 \\
\hline Genética & 14,56 & 4,67 & $32 \%$ & 4,00 & 0,06 & $39 \%$ & 18 \\
\hline Odontologia & 12,80 & 4,73 & $37 \%$ & 3,93 & 0,33 & $7 \%$ & 15 \\
\hline Engenharia Agrícola & 12,67 & 5,08 & $40 \%$ & 2,50 & 0,17 & $17 \%$ & 12 \\
\hline Engenharia Biomédica & 10,33 & 5,75 & $56 \%$ & 6,25 & 0,33 & $75 \%$ & 12 \\
\hline Oceanografia & 9,17 & 4,25 & $46 \%$ & 3,17 & 0,17 & $8 \%$ & 12 \\
\hline Saúde Coletiva & 6,83 & 1,25 & $18 \%$ & 2,92 & 0,08 & $0 \%$ & 12 \\
\hline Engenharia Nuclear & 6,10 & 4,10 & $67 \%$ & 2,00 & 0,80 & $50 \%$ & 10 \\
\hline Geral para Brasil & 10,36 & 4,56 & $44 \%$ & 4,72 & 0,37 & $28 \%$ & 889 \\
\hline
\end{tabular}

Fonte: Elaboração própria com base no Survey Brasi

Entre o número de projetos, pode-se ver que existe uma quantidade muito maior de financiamentos nacionais que internacionais. Medicina é a área que mais tem projeto com financiamento nacional, seguida por saúdes relacionadas à bioquímica, engenharia química, engenharia mecânica, aeroespacial e naval e zootecnia. Por outro lado engenharia de produção, engenharia nuclear e engenharia agrícola são os que apresentam, em média, o menor número de projetos. Quanto ao financiamento por instituições internacionais a ciência com maior número de projetos em média é a zootecnia seguido por outras áreas da saúde. Apenas essas duas ciências tem pelo menos um projeto com financiamento internacional por grupo. Assim, em muitos campos da ciência essa forma não é tanto utilizada e apresentam valor muito baixo, como é o caso da genética, saúde coletiva e engenharia de produção.

Os pedidos ou concessões de patentes apresentam uma distribuição bem heterogênea dos percentuais dentre as áreas de conhecimento. Em engenharia biomédica e física mais de 60\% dos grupos têm algum pedido ou concessão de patentes. Esse valor se reduz um pouco, mas, ainda se mantém elevado para as áreas de química, engenharia química, e engenharia nuclear. Oposto a esses campos, outros apresentam taxas muito baixas. Em saúde coletiva não foi realizado nenhum pedido ou concessão de patentes ${ }^{4}$. Outras áreas como recursos ambientais e engenharias afins, geociência, odontologia, oceanografia, e zootecnia registraram valores menores que $10 \%$. Ainda pode-se notar que mesmo áreas com um grande número de instituições de pesquisa estabelecidas, como agricultura e engenharia agrícola, têm média da taxa de patente baixa, sendo de 15\% e 17\% respectivamente. Esse dado também serve como um indicador para analisar em quais áreas o Brasil vem desenvolvendo resultados práticos de suas pesquisas e poder fomentar a instalação de um parque industrial em setores relacionados. Entretanto, cabe salientar que o pedido de patente incorre em custos que os grupos de pesquisa nem sempre têm condições de arcar (CUMMINGS e KIESLER, 2007). Dessa forma o desenvolvimento tecnológico nem sempre é medido

${ }^{4}$ Isso pode está relacionado a características intrínsecas a área do conhecimento. 
por essa variável ${ }^{5}$.

\subsection{Análise de histogramas de distribuição}

A FIGURA 1 apresenta os dois indicadores dos tipos de interação como definidos no QUADRO 1 . Nota-se que esses indicadores trazem uma distribuição relativamente homogênea dentre os grupos de pesquisa. No indicador 1 , os intervalos de escores de 0 a 0,5 se mantiveram muito próximo aos $10 \%$, o que indica uma variabilidade muito pequena entre os decis. A maior concentração se dá no intervalo entre 0,5 e 0,6 que apresenta valor superior a $15 \%$. Os valores do intervalo de 0,6 a 0,8 são similares àqueles menores que 0,5. Entretanto, os valores de maior importância apresentam as menores concentrações. A média dessa medida é 0,47 e o desvio o padrão de 0,25.

O segundo indicador, aquele que trata da relação universidade-empresa na forma de $P \& D$, também apresenta uma distribuição bastante simétrica. Entretanto, algumas diferenças devem ser ressaltadas, como a concentração de grupos de pesquisa que dão pouco valor para esse tipo de interação, valores menores que 0,1, está acima de $10 \%$. Assim, como no indicador 1 a maior concentração se dá entre 0,5 e 0,6, ou seja, um maior número de grupos que dão avaliação média para essa dimensão. Porém, existe um número maior de grupos concentrados na última parcela da distribuição, com aproximadamente $10 \%$. A média foi de 0,49 e o desvio padrão de 0,3 .

Essas duas figuras demonstram que os indicadores criados para os principais tipos de interação não apresentam concentrações em nenhum nível de resposta. Sendo assim, espera-se que seja possível classificar padrões de tipos de interação diferente nos grupos de pesquisa por área de conhecimento. Isso poderá ser visto tanto na medida de importância bruta quanto na medida de desvio da média que serão apresentadas na subseção seguinte.

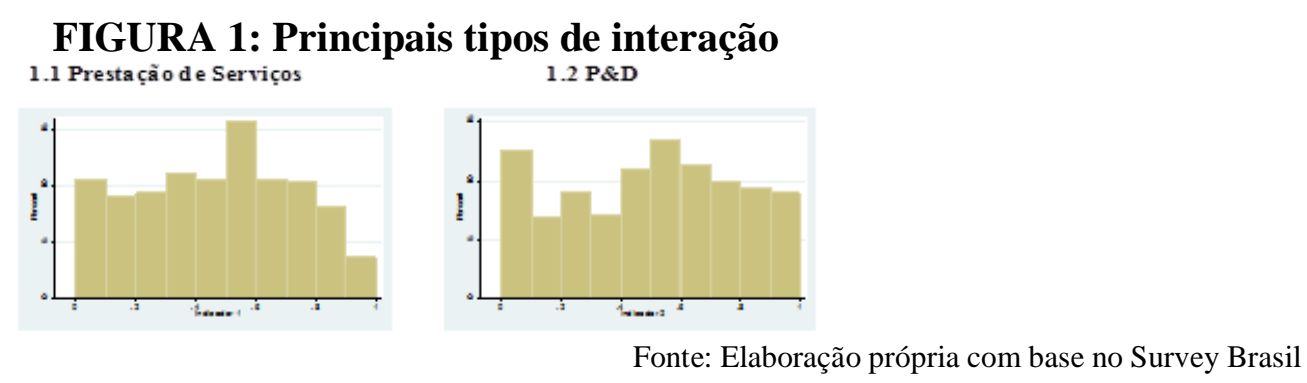

A questão sobre resultados foi dividida em três indicadores, um primeiro que traduz a avaliação dos chefes dos grupos de pesquisa a base científica, outro nos resultados relacionados a inovação e um terceiro na formação acadêmica. A FIGURA 2 apresenta os respectivos histogramas de distribuição das respostas.

Os resultados relacionados à base científica demonstram que a maioria dos grupos deu um valor alto para esse campo. Esse ponto vai de desencontro ao trabalho de Arocena e Sutz (2003) e evidencia a importância significativa que os pesquisadores brasileiros dão para os resultados científicos. A média desse indicador foi de 0,67 e o desvio padrão de 0,31 . Por outro lado, o indicador que coloca a importância da inovação para os grupos de pesquisa tem resultado muito baixo na média. Mais de $20 \%$ dos grupos atribuem valores entre 0 e 0,1 para essa distribuição. Isso pode ser utilizado como evidência da baixa taxa de inovação da economia nacional como encontrado em outras pesquisas a exemplo da PINTEC. Aqueles que dão valores acima de 0,9 somam apenas 3\% dos grupos. A média desse indicador é de 0,37 e se caracteriza por ser a menor dentre as três dimensões. O desvio padrão é de 0,29 . Por fim o terceiro indicador demonstra como a formação acadêmica é tida como muito importante na média dos grupos. Esse resultado vai de total acordo com aquele encontrado em Klevorick et all. (1994) e Schartinger et all (2001) que

\footnotetext{
${ }^{5}$ Lundvall (2002) a partir de uma pesquisa de interação entre universidade e empresa para a Dinamarca demonstra como que o país estabelece um desenvolvimento tecnológico muito mais atrelado a tecnologias de baixo retorno. Essas são raramente patenteadas e por isso não são medidas por esse indicador, porém, contribuem para o desenvolvimento do sistema nacional de inovação dinamarquês.
} 
colocam como papel mais importante para a universidade formar recursos humanos. Pode-se dizer que $60 \%$ dos grupos dão a esse indicador um valor maior que 0,8 . Não por menos ele apresenta como o de maior media na análise, 0,77. O desvio padrão é 0,28.

\section{FIGURA 2: Resultados da interação}

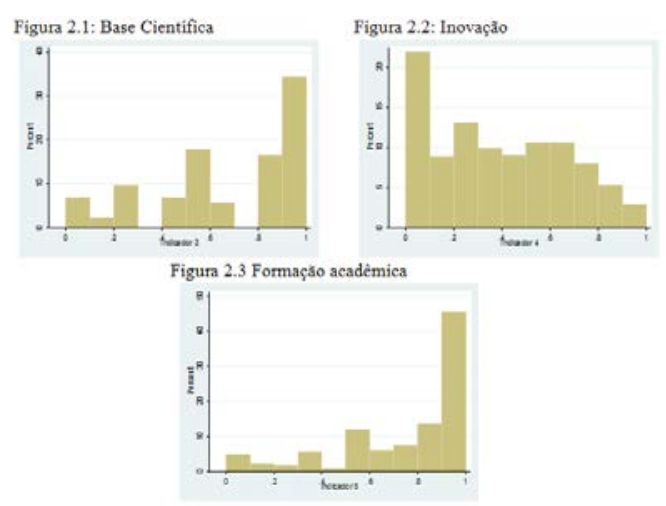

Fonte: Elaboração própria com base no Survey Brasil

Os benefícios também foram divididos em três indicadores, que são apresentados na Figura 3 pelos seus respectivos histogramas de distribuição das respostas. Esses indicadores apresentam médias elevadas. O indicador de informação/conhecimento que capta as novas ideias e projetos da interação dos grupos de pesquisa com as empresas, teve uma concentração clara nos níveis mais altos. Quase $40 \%$ da amostra deu a ele um valor superior a 0,9 e um número muito baixo lhe deu pouca importância. Esse indicador obteve uma média muito próxima do indicador de formação acadêmica, 0,76, sendo a segunda maior e um desvio padrão de 0,28 que reforça sua concentração em níveis elevados. Isso fortalece o fato demonstrado em Suzigan et. all (2013) em que os grupos de pesquisa desejam manter uma relação duradoura com as empresas compreendidas por vários projetos.

O indicador de desenvolvimento de recursos pode ser claramente separado em dois grupos. Um que lhe dá muita importância, com valores maiores que 0,6 e outro de pouca importância, com valores menores que 0,4. Isso é um indício de heterogeneidade dentre as áreas do conhecimento no tratamento dos pesquisadores para esse indicador. A explicação para isso se dá no fato de que a pesquisa em algumas ciências, como engenharias em geral, incorre em muitos custos e a interação tem como um dos objetivos o financiamento ${ }^{6}$. Como o grupo que dá muita importância supera aquele de pouca importância, a média é alta, sendo de 0,60. O desvio padrão é de 0,31.

Reputação e networking é um indicador formado por poucas variáveis e, assim como o indicador de base científica, não tem um histograma completo para todas as faixas de valores. Porém, observa-se que sua importância é muito forte para os grupos de pesquisa. Em torno de 50\% dos grupos atribuem um valor maior que 0,8 para tal. Esse ponto está relacionado com o que foi encontrado em Bekker e BodasFreitas (2008) no que diz respeito ao número crescente de interações. Além disso, o fato de que a rede de contatos e bons projetos executados são necessários para que os grupos continuem suas pesquisas e interações e ainda reduzir os custos de transação presente na prospecção. (Cummings e Kiesler, 2007) Podese dizer que os grupos dão importância para o learn by interacting. A média desse indicador 0,65 e o desvio padrão de 0,34 .

\footnotetext{
${ }^{6}$ Lima e Barbosa (2013) em um trabalho no qual colhem uma série de entrevista com pesquisadores de grupos de pesquisas de engenharia elétrica em Pernambuco. Eles concluem que a lei dos fundos setoriais, a qual exige que as empresas de energia elétrica invistam em interações com universidades, capacita grupos de pesquisa pernambucanos com equipamentos de forma a possibilitar a pesquisa de ponta na área.
} 

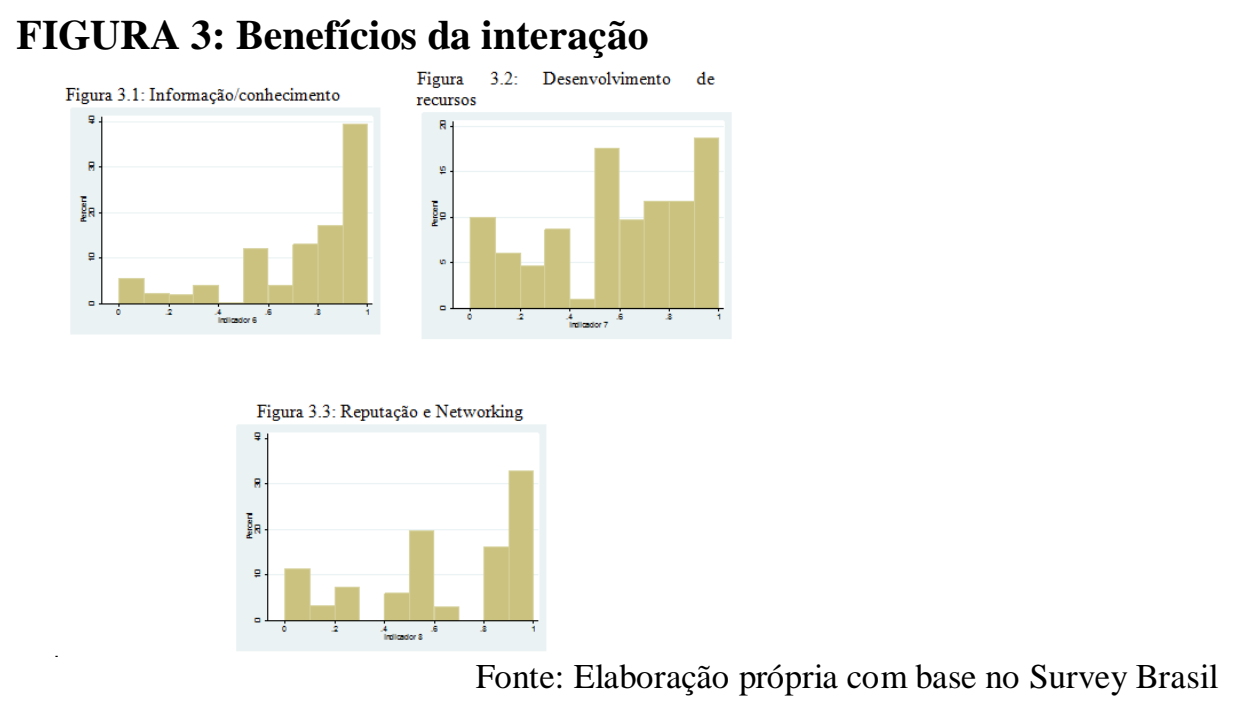

\subsection{Análise por áreas de conhecimento}

A TABELA $2^{7}$ mostra a taxa de importância absoluta e o desvio da média para cada um dos indicadores separados por áreas do conhecimento. As ciências estão distribuídas de acordo com as grandes áreas do conhecimento ${ }^{8}$. Sendo assim, primeiro são apresentados os campos relacionados às ciências agrárias, seguido pelas ciências biológicas, ciências da saúde, ciências exatas e da terra e, por fim, as engenharias. Em geral, foram encontrados valores baixos para as áreas relacionadas a ciências biológicas, ciências da saúde e ciências exatas e da terra. Por outro lado, os grupos de ciência agrária e engenharias deram valores maiores. A análise a seguir será realizada em subseções divididas para cada uma das dimensões.

\subsubsection{Tipos de interação}

Para a primeira dimensão, tipos de interação, nota-se que o indicador de Prestação de Serviço teve importância absoluta maior para engenharia agrícola, ciência e tecnologia de alimentos e engenharia nuclear. Os valores menores ficaram com as áreas de oceanografia, medicina e genética. Em termos do desvio da média, verifica-se, que a prestação de serviços assume uma maior relevância em ciência e tecnologia de alimentos e em diversos campos da engenharia como a engenharia nuclear e engenharia civil. Por outro lado, genética, medicina veterinária, e oceanografia tiveram resultados bem abaixo de 1. Esse indicador compreende atividades de pesquisa mais simples com base em conhecimento já consolidado. Porém, no caso brasileiro, assim como no conjunto dos países em desenvolvimento, ele também cumpre a função de antena do conhecimento gerado no exterior e realizado pelas universidades locais (RAPINI, 2007).

O outro indicador de tipo de relacionamento, $P \& D$, obteve os melhores resultados nas engenharias. Os grupos de engenharia de materiais, metalúrgica e minas e engenharia elétrica respectivamente foram os de maior valor, e, além desses, também se destaca zootecnia. Os menores valores ficaram para oceanografia, outras áreas de saúde e saúde coletiva. A medida de desvio da média assume maior relevância para os grupos de pesquisa das áreas de engenharia de materiais e metalúrgica e de minas, Ciência e Tecnologia de Alimentos e engenharia química contrastando com a menor relevância em Medicina, outras áreas da saúde, odontologia e oceanografia. Esse indicador é composto de variáveis de interação com maior conteúdo científico e de longo prazo (SUZIGAN ET ALL, 2011)

Comparando os dois indicadores notam-se características importantes. Os grupos de zootecnia obtiveram maiores valores de ambas as medida da TABELA 2 para as atividades em P\&D. Como foi demonstrado acima essa ciência foi a que mais recebeu financiamento de projetos do exterior. Assim, pode

\footnotetext{
${ }^{7}$ Para cada um dos indicadores foi marcado de azul os maiores valores e de com de rosa os menores com o intuito de facilitar a análise da TABELA 2.

${ }^{8}$ Isso pode ser identificado na TABELA 2 pelas linhas mais grossas de separação.
} 
ser sugerido que a integração em pesquisas internacionais contribui para gerar interações mais ligadas à pesquisa de ponta. Caso comprovado, esse fato deveria ser incentivado mais interações internacionais de modo a melhorar a atividade de pesquisa no Brasil e contribuir para a diminuição do atraso tecnológico ${ }^{9}$.

Nota-se também que um número maior de grupos dos campos das engenharias dá valor maior para atividades de $P \& D$ em relação a atividades de prestação de serviços. Isso ocorre para engenharia de materiais, metalúrgica e de minas, engenharia de produção, engenharia elétrica, engenharia mecânica, aeroespacial e naval e engenharia química. Esse fato pode ter duas explicações sendo que a primeira diz sobre a capacidade da universidade de gerar pesquisa se ponta nessas áreas. Por outro lado, isso também corrobora com o que foi colocado em Rapini (2007) e Rapini et. al. (2013) que as empresas brasileiras utilizam as universidades e seu aparato técnico para realizar suas atividades de pesquisa e desenvolvimento de produtos. Sendo assim, a empresa repassa parte do risco da inovação às universidades e não necessitam incorrer nos custos da atividade científica. Essa é uma característica do sistema nacional de inovação brasileiro como descrito em Bernardes e Albuquerque (2003). Para definir qual dos efeitos ocorre de fato seria necessária a aplicação de algum outro método de pesquisa que detalhasse melhor a situação, como, por exemplo, entrevistas e estudos de caso.

\subsubsection{Principais resultados}

Dentre aqueles indicadores que representam os principais resultados, as ciências que se destacam em importância absoluta para as descobertas de base científica são a engenharia de materiais, metalúrgica e minas, ciência tecnologia de alimentos e biologia geral, botânica e zoologia. Com os menores resultados estão engenharia de produção, engenharia sanitária e medicina. Na variação relativa observou que o incremento da base científica é mais importante para as áreas de biologia geral, botânica e zootecnia, engenharia de materiais e metalúrgica e de minas e tecnologia de alimentos contrastando com a menor importância desse indicador nas áreas de engenharia de produção, engenharia sanitária e medicina.

Para o indicador de inovação, como já foi demonstrado na análise de histograma, os grupos de pesquisa atribuíram importâncias muito baixas. Porém, abrindo para cada área de pesquisa observa-se que algumas têm resultados significativamente menores que as outras. Engenharia biomédica, biologia geral, botânica e zoologia e engenharia nuclear se destacam como as maiores porcentagens, enquanto que, geociências, oceanografia e saúde coletiva são os menores seguidos por ecologia. Essa medida apresentou escore menor que $10 \%$ em todas essas últimas ciências. Na análise relativa, a geração de inovações se destaca para engenharia de materiais e metalúrgica e de minas, ciência e tecnologia de alimentos e engenharia química. Por outro lado, oceanografia, ecologia e saúde coletiva apresentam valores menores que 0,5 .

O indicador de formação acadêmica teve os percentuais mais elevados para engenharia de produção, biologia geral, botânica e engenharia química. A menor taxa foi dada por farmácia e farmacologia com um valor de 50\% seguido por medicina e agronomia. A variação do índice de desvio da média é pouco significativa, entretanto, é observado um valor mais elevado para as áreas de engenharia elétrica, geociências e ecologia, e menores para as áreas de Medicina e Farmácia e Farmacologia. Esse é o indicador com maior importância, 78,3\%, fato que já tinha sido observado na análise de histogramas.

Algumas observações também podem ser feita a essa dimensão. Como por exemplo, áreas de pesquisa que são consideradas inovadoras no Brasil, como o caso da agricultura, e conhecidas por inovação no mundo, como genética e farmácia e farmacologia, deram importância absoluta menor que 20\% para o indicador de inovação. Ainda cabe ressaltar que esse indicador apresentou altos valores médios para as áreas científicas que tem um número significativo de grupos com patentes. Isso pode ser observado para engenharia biomédica, química, engenharia química e engenharia nuclear. Entretanto, O campo de farmácia e farmacologia obteve deu um valor alto de importância para a base científica, o que demonstra certa incapacidade de transformar as descobertas em produtos e mesmo na criação de empresas no setor.

Assim como já havia sido demonstrado no trabalho de Klevorick et. all (1995) e Schartinger et. all

\footnotetext{
${ }^{9}$ Projetos conjuntos com instituições exteriores incorrem em problemas de direito de propriedade sobre os resultados da pesquisa realizada. Sendo assim, as questões institucionais devem ser resolvidas em contratos de modo que o país consiga usufruir dos resultados.
} 
(2001) a formação de capital humano é um fator muito importante na interação universidade e empresa. O indicador que capta esse fator foi o maior da base com nota de 78,3\%. Além disso, apenas em 3 ciências tiveram menos de $70 \%$ dos grupos lhe deram importância. O campo de engenharia de produção é emblemático para explicar essa questão. Dentro da dimensão dos principais resultados essa ciência deu importância absoluta baixa tanto para base científica quanto para inovação, porém, foi a que mais se destacou em formação acadêmica com 92,3\% dos grupos. Isso pode ser explicado pela característica dessa engenharia que se difere das outras da sua área científica e se relaciona mais com capacitação de pessoal.

\subsubsection{Benefícios}

O indicador de informação/conhecimento da dimensão dos benefícios também obteve valores médios muito altos, e assim, como no indicador de formação acadêmica as menores taxas de importância são de apenas 50\%, nesse caso, para medicina, oceanografia e engenharia biomédica. Dentre os mais altos destacam-se biologia geral, botânica e zoologia, engenharia de materiais, metalúrgica e minas e engenharia civil. Além desses, engenharia elétrica e recursos ambientais e engenharias afins também apresentaram valores altos, acima de $90 \%$. A medida de desvio da média para o indicador mostrou-se relativamente mais elevado nas áreas de recursos ambientais e engenharias afins, engenharia de materiais e metalúrgica e de minas e ciência e tecnologia de alimentos. Por outro lado, uma menor importância está nas áreas de engenharia biomédica Oceanografia.

O indicador de desenvolvimento de recursos teve uma taxa de importância maior para engenharia de materiais, metalúrgica e minas e engenharia mecânica. Isso pode ser explicado pela necessidade que esses campos têm de aparelhar seus laboratórios em detrimento daqueles que deram menor importância para o indicador como engenharia de produção, saúde coletiva e outras áreas da saúde. A medida de desvio da média assume maior relevância relativa em zootecnia, engenharia civil e engenharia de materiais e metalúrgica e minas, contrastando com valores relativamente mais baixos em saúde coletiva, outras áreas relacionadas à saúde e engenharia de Produção.

A reputação e networking são tidos como mais importante na engenharia de materiais, metalúrgica e minas, engenharia de produção, engenharia elétrica e saúdes relacionadas à bioquímica. As áreas que dão menor importância são medicina, outras áreas de saúde, oceanografia e engenharia biomédica. O indicador de reputação dos grupos e as práticas de networking apresenta o índice de desvio da média alto para as áreas de ciência e tecnologia de alimentos, engenharias de materiais e metalúrgica e de minas e menor relevância nas áreas de medicina, oceanografia e engenharia biomédica.

Os benefícios se diferenciam dos resultados por serem contribuições tácitas da interação entre universidades e empresas. Nesse ponto, podem-se observar diferenças bastante significativas entre as áreas como a necessidade de recursos de grupos relacionados a engenharias em detrimento daqueles grupos de agronomia (LIMA e BARBOSA, 2011). Como já foi dito, essa última ciência já tem uma infraestrutura de pesquisa montada que lhe possibilita a realização dos projetos enquanto que as primeiras vivem escassez constante de equipamentos. A área de genética também apresenta resultados baixos, o que se apresenta como um ponto interessante para análises futuras que não será desenvolvido aqui.

A reputação é um fator interessante para a continuação das interações, e esse fator teve altas notas em engenharias. Isso pode está relacionado ao fato de que os grupos essas áreas estão bastante ligados ao setor produtivo em que a competitividade é forte. Caso haja algum erro ou fracasso na atividade de pesquisa as consequências podem ser danosas às firmas e o grupo passa a não ser mais contatados. Além disso, como Lima e Barbosa (2011) demonstraram a lei dos fundos setoriais exige que as empresas do setor elétrico invistam em relações com universidades, porém, elas fazem isso ao seu contra gosto. Sendo assim, os grupos que recebem esse benefício deve estabelecer boas relações para que não o perca no futuro. 
TABELA 2: Medidas dos grupos de pesquisa separados por áreas de conhecimento

\begin{tabular}{|c|c|c|c|c|c|c|c|c|c|c|c|c|c|c|c|c|c|c|}
\hline \multirow[b]{3}{*}{ Área do conhecimento } & \multirow{3}{*}{$\begin{array}{l}\text { Número } \\
\text { de grupos }\end{array}$} & \multicolumn{4}{|c|}{ Questão 1: tipos de relacionamento } & \multicolumn{6}{|c|}{ Questão 2: principais resultados } & \multicolumn{6}{|c|}{ Questão 3: benefícios } & \multirow{3}{*}{$\begin{array}{l}\text { Média geral } \\
\text { de score para } \\
\text { indicadores }\end{array}$} \\
\hline & & \multicolumn{2}{|c|}{\begin{tabular}{c|}
$\begin{array}{c}\text { Prestação de } \\
\text { serviços }\end{array}$ \\
\end{tabular}} & \multicolumn{2}{|c|}{ P\&D } & \multicolumn{2}{|c|}{ Base científica } & \multicolumn{2}{|c|}{ Inovação } & \multicolumn{2}{|c|}{\begin{tabular}{|c|}
$\begin{array}{c}\text { Formação aca- } \\
\text { dêmica }\end{array}$ \\
\end{tabular}} & \multicolumn{2}{|c|}{$\begin{array}{l}\text { Informação/ } \\
\text { conhecimento }\end{array}$} & \multicolumn{2}{|c|}{$\begin{array}{c}\text { Desenvolvimento } \\
\text { de recursos }\end{array}$} & \multicolumn{2}{|c|}{$\begin{array}{c}\text { Reputação e } \\
\text { Networking } \\
\end{array}$} & \\
\hline & & Absoluto & Desvio & Absoluto & Desvio & Absoluto & Desvio & Absoluto & Desvio & Absoluto & Desvio & Absoluto & Desvio & Absoluto & Desvio & Absoluto & Desvio & \\
\hline Agronomia & 85 & $30,6 \%$ & 0,98 & $40,0 \%$ & 1,10 & $65,9 \%$ & 1,04 & $14,1 \%$ & 0,71 & $65,9 \%$ & 0,92 & $85,9 \%$ & 1,04 & $43,5 \%$ & 0,88 & $62,4 \%$ & 0,92 & 0,96 \\
\hline Ciência e Tecnologia de Alimentos & 25 & $60,0 \%$ & 1,32 & $56,0 \%$ & 1,36 & $80,0 \%$ & 1,16 & $52,0 \%$ & 1,54 & $92,0 \%$ & 1,06 & $92,0 \%$ & 1,12 & $64,0 \%$ & 1,12 & $80,0 \%$ & 1,23 & 1,24 \\
\hline Engenharia Agrícola & 12 & $66,7 \%$ & 1,20 & $41,7 \%$ & 1,03 & $66,7 \%$ & 1,06 & $25,0 \%$ & 1,07 & $83,3 \%$ & 1,08 & $83,3 \%$ & 0,95 & $75,0 \%$ & 1,11 & $66,7 \%$ & 1,04 & 1,02 \\
\hline Medicina Veterinária & 24 & $25,0 \%$ & 0,82 & $20,8 \%$ & 0,70 & $66,7 \%$ & 1,02 & $16,7 \%$ & 0,62 & $75,0 \%$ & 0,92 & $70,8 \%$ & 0,91 & $50,0 \%$ & 0,90 & $50,0 \%$ & 0,87 & 0,84 \\
\hline Recursos ambientais e engenharias afins & 31 & $45,2 \%$ & 1,17 & $41,9 \%$ & 1,17 & $67,7 \%$ & 1,05 & $19,4 \%$ & 0,92 & $87,1 \%$ & 1,08 & $90,3 \%$ & 1,13 & $67,7 \%$ & 1,15 & $74,2 \%$ & 1,10 & 1,09 \\
\hline Zootecnia & 22 & $36,4 \%$ & 1,02 & $59,1 \%$ & 1,15 & $72,7 \%$ & 1,12 & $36,4 \%$ & 1,04 & $81,8 \%$ & 1,06 & $86,4 \%$ & 1,02 & $68,2 \%$ & 1,18 & $63,6 \%$ & 0,90 & 1,02 \\
\hline Biologia Geral; Botânica e Zoologia & 25 & $28,0 \%$ & 0,91 & $40,0 \%$ & 0,88 & $84,0 \%$ & 1,21 & $20,0 \%$ & 0,71 & $88,0 \%$ & 1,07 & $80,0 \%$ & 1,01 & $72,0 \%$ & 1,12 & $64,0 \%$ & 0,87 & 0,98 \\
\hline Ecologia & 22 & $31,8 \%$ & 0,91 & $40,9 \%$ & 0,88 & $68,2 \%$ & 1,01 & $9,1 \%$ & 0,46 & $81,8 \%$ & 1,10 & $81,8 \%$ & 0,99 & $68,2 \%$ & 1,09 & $68,2 \%$ & 0,94 & 0,90 \\
\hline Genética & 18 & $22,2 \%$ & 0,63 & $50,0 \%$ & 1,19 & $72,2 \%$ & 1,12 & $11,1 \%$ & 0,81 & $88,9 \%$ & 1,07 & $88,9 \%$ & 1,07 & $38,9 \%$ & 0,88 & $72,2 \%$ & 1,03 & 0,97 \\
\hline Saúde relacionadas à bioquímica & 36 & $33,3 \%$ & 0,92 & $38,9 \%$ & 1,03 & $69,4 \%$ & 1,04 & $19,4 \%$ & 1,04 & $66,7 \%$ & 0,93 & $69,4 \%$ & 0,94 & $61,1 \%$ & 1,03 & $80,6 \%$ & 0,90 & 1,01 \\
\hline Farmácia e Farmacologia & 22 & $36,4 \%$ & 0,98 & $50,0 \%$ & 1,18 & $68,2 \%$ & 1,01 & $18,2 \%$ & 1,03 & $50,0 \%$ & 0,72 & $68,2 \%$ & 0,86 & $63,6 \%$ & 0,99 & $45,5 \%$ & 0,96 & 1,05 \\
\hline Medicina & 32 & $21,9 \%$ & 0,81 & $21,9 \%$ & 0,64 & $53,1 \%$ & 0,82 & $21,9 \%$ & 0,80 & $53,1 \%$ & 0,77 & $50,0 \%$ & 0,71 & $43,8 \%$ & 0,89 & $40,6 \%$ & 0,73 & 0,79 \\
\hline Odontologia & 15 & $26,7 \%$ & 0,83 & $20,0 \%$ & 0,62 & $66,7 \%$ & 1,01 & $26,7 \%$ & 0,86 & $86,7 \%$ & 1,01 & $73,3 \%$ & 0,90 & $46,7 \%$ & 1,02 & $60,0 \%$ & 0,91 & 0,94 \\
\hline Saúde Coletiva & 12 & $25,0 \%$ & 0,83 & $16,7 \%$ & 0,63 & $66,7 \%$ & 0,84 & $8,3 \%$ & 0,49 & $75,0 \%$ & 0,96 & $75,0 \%$ & 0,96 & $33,3 \%$ & 0,68 & $58,3 \%$ & 0,82 & 0,80 \\
\hline Outras áreas de saúde & 29 & $24,1 \%$ & 0,85 & $13,8 \%$ & 0,48 & $58,6 \%$ & 0,91 & $20,7 \%$ & 0,70 & $82,8 \%$ & 1,01 & $65,5 \%$ & 0,83 & $34,5 \%$ & 0,69 & $44,8 \%$ & 0,84 & 0,82 \\
\hline $\begin{array}{l}\text { Ciência da Computação, matemática e probabili- } \\
\text { dade }\end{array}$ & 50 & $40,0 \%$ & 1,00 & $48,0 \%$ & 1,21 & $60,0 \%$ & 1,00 & $40,0 \%$ & 1,26 & $80,0 \%$ & 0,99 & $86,0 \%$ & 1,05 & $62,0 \%$ & 1,04 & $74,0 \%$ & 1,12 & 1,08 \\
\hline Física & 18 & $22,2 \%$ & 0,77 & $33,3 \%$ & 0,96 & $66,7 \%$ & 1,03 & $33,3 \%$ & 1,22 & $72,2 \%$ & 0,98 & $77,8 \%$ & 0,90 & $66,7 \%$ & 1,07 & $61,1 \%$ & 1,03 & 1,03 \\
\hline Geociências & 36 & $25,0 \%$ & 1,05 & $33,3 \%$ & 0,89 & $75,0 \%$ & 1,09 & $8,3 \%$ & 0,51 & $88,9 \%$ & 1,11 & $86,1 \%$ & 1,05 & $55,6 \%$ & 0,99 & $61,1 \%$ & 0,98 & 0,97 \\
\hline Oceanografia & 12 & $16,7 \%$ & 0,67 & $8,3 \%$ & 0,53 & $66,7 \%$ & 1,02 & $8,3 \%$ & 0,39 & $75,0 \%$ & 1,00 & $50,0 \%$ & 0,68 & $58,3 \%$ & 0,95 & $50,0 \%$ & 0,81 & 0,75 \\
\hline Química & 40 & $27,5 \%$ & 0,86 & $40,0 \%$ & 1,01 & $62,5 \%$ & 0,96 & $25,0 \%$ & 0,96 & $70,0 \%$ & 0,94 & $77,5 \%$ & 0,94 & $60,0 \%$ & 1,02 & $52,5 \%$ & 0,88 & 0,93 \\
\hline Engenharia Biomédica & 12 & $58,3 \%$ & 1,19 & $58,3 \%$ & 1,12 & $75,0 \%$ & 1,08 & $58,3 \%$ & 1,43 & $75,0 \%$ & 1,07 & $58,3 \%$ & 0,76 & $50,0 \%$ & 0,86 & $50,0 \%$ & 0,80 & 1,08 \\
\hline Engenharia Civil & 48 & $54,2 \%$ & 1,24 & $39,6 \%$ & 0,95 & $66,7 \%$ & 1,06 & $25,0 \%$ & 1,08 & $87,5 \%$ & 1,07 & $91,7 \%$ & 1,12 & $66,7 \%$ & 1,17 & $72,9 \%$ & 1,10 & 1,06 \\
\hline Engenharia de Materiais e Metalúrgica e de Minas & 64 & $50,0 \%$ & 1,22 & $68,8 \%$ & 1,42 & $87,5 \%$ & 1,14 & $46,9 \%$ & 1,56 & $81,3 \%$ & 1,01 & $92,2 \%$ & 1,13 & $76,6 \%$ & 1,17 & $87,5 \%$ & 1,21 & 1,21 \\
\hline Engenharia de Produção & 26 & $26,9 \%$ & 1,09 & $42,3 \%$ & 1,00 & $42,3 \%$ & 0,75 & $23,1 \%$ & 1,16 & $92,3 \%$ & 1,10 & $80,8 \%$ & 1,03 & $30,8 \%$ & 0,76 & $84,6 \%$ & 1,16 & 0,98 \\
\hline Engenharia Elétrica & 62 & $40,3 \%$ & 1,11 & $61,3 \%$ & 1,30 & $59,7 \%$ & 0,98 & $45,2 \%$ & 1,41 & $82,3 \%$ & 1,05 & $90,3 \%$ & 1,08 & $67,7 \%$ & 1,12 & $80,6 \%$ & 1,15 & 1,12 \\
\hline Engenharia Mecânica, aeroespacial e naval & 53 & $35,8 \%$ & 0,96 & $49,1 \%$ & 1,11 & $62,3 \%$ & 0,90 & $32,1 \%$ & 1,28 & $79,2 \%$ & 0,92 & $84,9 \%$ & 0,98 & $75,5 \%$ & 1,01 & $71,7 \%$ & 1,02 & 1,00 \\
\hline Engenharia Nuclear & 10 & $60,0 \%$ & 1,26 & $40,0 \%$ & 0,92 & $70,0 \%$ & 0,95 & $50,0 \%$ & 1,31 & $80,0 \%$ & 0,97 & $70,0 \%$ & 1,01 & $70,0 \%$ & 1,12 & $70,0 \%$ & 0,96 & 1,08 \\
\hline Engenharia Química & 29 & $48,3 \%$ & 1,12 & $58,6 \%$ & 1,34 & $75,9 \%$ & 1,08 & $44,8 \%$ & 1,50 & $89,7 \%$ & 1,07 & $86,2 \%$ & 0,98 & $62,1 \%$ & 0,98 & $75,9 \%$ & 1,01 & 1,11 \\
\hline Engenharia Sanitária & 19 & $36,8 \%$ & 1,13 & $31,6 \%$ & 0,89 & $52,6 \%$ & 0,76 & $26,3 \%$ & 0,91 & $73,7 \%$ & 0,97 & $84,2 \%$ & 1,02 & $47,4 \%$ & 0,92 & $63,2 \%$ & 0,91 & 0,98 \\
\hline Total & 889 & $36,6 \%$ & 1,00 & $43,2 \%$ & 1,00 & $67,2 \%$ & 1,00 & $27,8 \%$ & 1,00 & $78,3 \%$ & 1,00 & $81,4 \%$ & 1,00 & $59,2 \%$ & 1,00 & $67,5 \%$ & 1,00 & 1,00 \\
\hline Score da importância do Indicados & & & $\mathbf{0 , 4 6}$ & & $\mathbf{0 , 4 7}$ & & $\mathbf{0 , 6 6}$ & & $\mathbf{0 , 3 7}$ & & $\mathbf{0 , 7 7}$ & & $\mathbf{0 , 5 9}$ & & $\mathbf{0 , 5 9}$ & & 0,64 & \\
\hline
\end{tabular}

Fonte: Elaboração própria com base no Survey Brasil 
No tocante à média geral dos indicadores para as ciências, última coluna da TABELA 2, foi observado valores mais elevados para as áreas de Ciência e Tecnologia de Alimentos, Engenharia de Materiais e Metalúrgica e de minas, Engenharia Elétrica. As áreas com valores relativamente mais baixos são oceanografia, medicina e saúde coletiva. Isso mostra uma característica interessante da pesquisa no que diz a respeito da medicina. Essa ciência é de suma importância para a constituição de um sistema nacional de saúde que é uma parte necessária do sistema inovação de um país. Esse baixo valor pode estar relacionado a duas coisas. A primeira delas diz que os chefes dos grupos têm mais rigor para responder essas questões, e, sendo assim lhes dão notas menores em todas as dimensões. A outra hipótese está relacionada ao fato de que as os respondentes dessa ciência avaliam com pouca qualidade as interações. Esse segundo ponto seria mais complicado, pois, evidenciaria uma falha de coordenação entre as duas pontas (universidade-empresa). O trabalho não adentrará nessas questões, porém sabe que é de suma necessidade realizar pesquisas adicionais na área.

O inverso do que foi dito para medicina também é valido para as ciências que obtiveram médias gerais altas. Uma evidencia interessante pode ser notada nos grupos de engenharia de minas e engenharia metalúrgica no trabalho de Chaves et all (2012). Eles demonstram como essa ciência interage com empresas de alguns setores em Minas Gerais com governança bem definida e institucionalidade forte. Além disso, a ciência na região tem uma história interessante que remete à Escola de Minas de Ouro Preto (SWCHARTZMAN, 1972).

\section{Considerações Finais}

Ao longo deste trabalho, procurou-se explorar algumas características da interação universidadeempresa no Brasil, do ponto de vista dos grupos de pesquisa atuantes em diferentes campos do conhecimento. Foi utilizado como fundo teórico a literatura de sistemas nacionais de inovação na qual se espera que a relação entre universidades e empresas seja virtuosa. Como demonstrado pelo trabalho de Bernardes e Albuquerque (2003) o sistema brasileiro é imaturo e isso pôde ser visto em algumas características apresentadas pela fragilidade de algumas ciências e da atividade inovativa.

Os dados demonstraram que, na dimensão de tipos de interação, os indicadores de prestação de serviço e de pesquisa e desenvolvimento (P\&D) obtiveram distribuições muito próximas da homogênea, ou seja, existem tanto grupos que lhe deram notas de importância altas, quanto, grupos que classificaram com baixa importância. Entretanto, quando observado para as ciências, pode-se dizer que algumas áreas, como física, química e mesmo agronomia tiveram resultados baixos para P\&D. Essas ciências têm história no sistema nacional de ciência e tecnologia como apresentado no trabalho de Schwartzman (1979). Esse fato merece maior atenção e uma pesquisa posterior de investigação. O método a ser utilizado seria o estudo de vários casos de sucesso e fracasso em interações com empresas por parte desses grupos de pesquisa.

Os principais resultados também expuseram uma debilidade do caso brasileiro. Em geral, as notas dadas para a dimensão de inovação ficaram a quem das outras duas dimensões. Isso expressa os vários fatores institucionais, organizacionais e econômicos que dificultam os grupos de pesquisa no Brasil para transformar suas pesquisas em produto. Outro fato que contribui para isso vem da baixa atividade inovativa do setor privado brasileiro como captado pela PINTEC. Como sugestão de política poderia ser pensada a construção e gestão de parques tecnológicos, flexibilização de alguns entraves colocados pelas agências reguladoras do país e canais específicos de financiamento mais efetivos. Porém, a dimensão trouxe resultados que corroboram com a literatura internacional em que a função principal da universidade no processo de interação com empresas é a formação de capital humano. (KLEVORICK ET. ALL, 1995; SCHARTINGER ET. ALL, 2001)

Para os benefícios, observou-se que, para o geral da base, um bom percentual dos grupos colocaram as três dimensões como importante. O menor desses valores ficou para o indicador de formação de recursos, porém, sabe-se que esse é muito importante para que se tenha continuidade em pesquisa de certas engenharias. Outro fato sobre o indicador é que em áreas como agronomia que já tem uma infraestru- 
tura desenvolvida pelo Estado ele não assume escores significativos. O indicador de reputação e networking demonstrou que em geral os grupos brasileiros estão preocupados em formação de redes de pesquisa e de feedback de seus projetos. Esse ponto também poderia ser explorado em pesquisas posteriores que visassem mapear tais redes e incentivar o fluxo de informação.

Um fato curioso foi encontrado no que diz aos baixos valores dados aos indicadores, em geral, pelo conjunto das ciências biológicas e ciências da saúde. O artigo sugere que isso pode ocorrer tanto por uma qualidade baixa das interações dessas grandes áreas do conhecimento quanto por um maior rigor dos pesquisadores desses campos na avaliação da pesquisa. Porém, para entender melhor o problema seria interessante recorrer à outra metodologia como o estudo de casos, e sendo assim, atuar da forma mais contundente para incentivar essas ciências que constituem um possível novo paradigma tecno-econômico, a biotecnologia.

\section{REFERÊNCIAS BIBLIOGRÁFICAS}

ALBUQUERQUE, E. (1999), National systems of innovation and non-OECD countries: notes about a tentative typology. Revista de Economia Política, v. 19, nº 4, p. 35-52.

AROCENA, R.; SUTZ, J. (2003), Knowledge, innovation and learning: systems and policies in the north and in the south. IN: CASSIOLATO, J.; LASTRES, H.; MACIEL, M. (eds.) Systems of Innovation and Development - Evidence from Brazil. Rio de Janeiro: Edward Elgar.

ARVANITS, S. et al. (2008), University-industry knowledge and technology transfer in Switzerland: What university scientists think about co-operation with private enterprises. Resarch Police, v. 37, p. 1865-1863.

ARZA, V. (2010), Chanel, benefits and risks of public-private interaction for knowledge transfer: a conceptual framework inspired by Latin America. Science and Public Police , v.37 p. 499-511.

BEKKERS, R.; BODAS-FREITAS, I. (2008), Analyzing knowledge transfer channels between universities and industry: To what degree do sectors also matter?. Research Police, v. 37, p.1838-1553.

BERNARDES, A.; ALBUQUERQUE, E. (2003), Cross-over, thresholds, and interactions between science and technology: lessons for less-developed countries, Research Police, v.32 p. 865-885.

BRANSCOMB, L. et al. (1 $1^{\mathrm{a}}$ ed), (1998), Industrial knowledge: University-industry linkages in Japan and the United State. Harvard: Harvard University.

BRITTO, J.; OLIVEIRA, B. (2011), Padrões setoriais de interação universidade-empresa no Brasil: um mapeamento de competências a partir de informações da pesquisa "Brazil Survey", Revista de Economia, v. 37, no 3, p. 167-212.

BOARDMAN, P.; PONOMARIOV, B. (2009), University researchers working with private companies, Technovation v.29, p.142-153, 2009.

COHEN, W. et al. (2002), Links and impacts: the influence of public R\&D on industrial research. Management Science, v. 48, no 1, p. 1-23.

COOKE. F. et al. (1998), Regional Systems of innovation: an evolutionary perspective, Environment and planning, v.30, p. 1563-1584.

COSTA, A. et al. (2011), Proximidade geográfica e interação universidade-empresa no Rio de Janeiro, Revista de Economia, v. 37, n 3, p. 213-238.

CUMMINGS, J.; KIESLER, S. (2007), Coordination costs and project outcomes in multi-university col- 
laborations, Research Policy, v.36, p. 1620-1634.

FRANCO, L. et al. (2010) Características da interação entre universidades e institutos públicos de pesquisa (IPPs) e empresas em Minas Gerais sob a perspectiva de ambos agentes do sistema estadual de inovação: notas introdutórias, in: XII SEMINÁRIO DE ECONOMIA MINEIRA, Diamantina. Anais... Belo Horizonte: CEDEPLAR.

FREEMAN, C; SOETE, L. (1ª Ed), ( 2008), A Economia da inovação industrial, Campinas: Editora da Unicamp.

FUENTES, C.; DUTRÉNIT,G. (2012), Best channels of academia-industry interaction for long-term benefit, Research Police, v. 41, p. 1666-1682.

GARCIA, R. et al. (2011), Os efeitos da proximidade geográfica para o estímulo da interação universidade-empresa, Revista de Economia, v. 37, n 3, p. 307-330.

GIBBONS, M. et al. (1994), The new production of knowledge: the dynamics of science and research in contemporary societies, London: Sage Publications.

JOHNSON, B. (2008), Cities, systems of innovation and economic development. Innovation: Management, Policy \& Practice, v. 10, n³, 146-155.

JOHNSON, B. (1992), Toward a new approach to National System of innovation. In: LUNDVALL, B. A. National Systems of Innovation: towards a Theory of Innovation and Interactive Learning. London: Printer Publishers.

KLEVORICK, A. et al. (1995), On the sources and significance of interindustry differences in technological opportunities. Research Policy, v 24 , p.185-205.

LASTRES, H. et, al. (2002) Interagir para competir: promoção de arranjos produtivos e inovativos no Brasil. Brasília: SEBRAE.

LIMA, J.; BARBOSA, M. (2013), Interação universidade-empresa e o processo de inovação em Pernambuco: o caso da engenharia elétrica e o setor de eletricidade e gás, Conferência Internacional do LALICS2013, Rio de Janeiro. Anais..., Latin America network for economics of learning, innovation and competence building systems: México.

LIST, F. (2 ${ }^{\mathrm{a}}$ Ed) (1983), Sistema nacional de economia política. 1.ed. São Paulo: Abril Cultural.

LUNDVALL, B. (1992), Introduction In: LUNDVALL, B. A. National Systems of Innovation: towards a Theory of Innovation and Interactive Learning. London: Printer Publishers.

LUNDVALL, B. (2002), The university in the learning economy. Aalborg: DRUID, (texto para discussão)

LUNDVALL, B. (2005), National Innovation Systems - Analytical concept and development tools, in: DRUID-CONFERENCE, Copenhagen. Anais... Copemhagen: DRUID.

MALERBA, F. (2002), Sectoral systems of innovation and production. Research Policy, v.31, p.247-264.

MAZZOLENI, R.; NELSON, R. (2007), Public research institutions and economic catch-up. Research Police, v. 36, p. 1512-1528.

MOWERY, D. et al. (2004), Ivory tower and industrial innovation: university-industry technology trans- 
fer before and after the Bayh-Dole Act. Stanford: Stanford University.

NARIN, F. (1997), et al. The increasing linkage between U.S. technology and public science. Research Policy, v. 26, p. 317-330.

NELSON, R. (1 ${ }^{\mathrm{a}}$ Ed), (1993), National Innovation Systems: a comparative analysis. New York: Oxford University.

PERKMANN, M. WALSH, K. (2008), Engaging the scholar: three types of academic consulting and their impact on university and industry. Research Policy. v 37 p. 1884-1891.

PINHO, M., (2011), A visão das empresas sobre a relação entre universidade e empresas no Brasil: Uma análise baseada nas categorias de intensidade tecnológica. Revista de Economia, v. 37, nº 3, p. 279-306.

PÓVOA, L; MONSUETO, S. (2011), Tamanho das empresas, interação com as universidades e inovação. Revista de Economia, v. 37, no 3, p. 7-21.

RAPINI, M. (2004), Interação Universidade- Indústria no Brasil: Uma análise exploratória a partir do Diretório de Pesquisas do CNPq. 2004. Dissertação (Mestrado em Economia) - Instituto de Economia, Universidade Federal do Rio de Janeiro, Rio de Janeiro.

RAPINI, M. (2007), Interação Universidade-Empresa no Brasil: Evidências do Diretório dos Grupos de Pesquisa do CNPq. Estudos. Econômicos, São Paulo, 37, p. 211-233.

RAPINI, M. et al. (2013), Innovation System and development in Latin America: University-Industry interactions in Brazil, in XVIII ENCONTRO NACIONAL DE ECONOMIA POLÍTICA, Belo Horizonte. Anais... São Paulo: SEP.

ROSENBERG, N. (1 $1^{\text {a }}$ ed) (1982), Inside the balck box: technology and economics. Cambridge: Cambridge University.

SARTORIS, A. (2003), Estatística e introdução à econometria. São Paulo: Editora Saraíva.

SCHARTINGER, D. et al. (2001), Interactive relations between universities and firms: empirical evidence for Austria. Journal of Technology Transfer, v. 26, p.255-268.

SCHARTINGER, D. et al. (2002), Knowledge interactions between universities and industry in Austria: sectorial patterns and determinants. Research Police, v. 31, p.303-328.

SCHWARTZMAN, S. (1 ${ }^{\text {a }}$ Ed), (1979), Formação da comunidade científica no Brasil. 1 ed. Rio de Janeiro: Editora da FINEP.

SILVA NETO, F. et al. (2011), A interação universidade/instituto público de pesquisa e empresa n€o Brasil: resultados comparativos entre o relacionamento com empresas nacionais e multinacionais. Revista de Economia, v. 37, $\mathrm{n}^{\mathrm{o}}$ 3, p. 117-140.

SILVA, L. A. (2003) Padrões de interação entre ciência e tecnologia: uma investigação a partir de estatísticas de artigos e patentes. 2003. Dissertação (Mestrado em economia) - Centro de desenvolvimento e Planejamento Regional, Universidade Federal de Minas Gerais, Belo Horizonte.

SUTZ, J. (2000), The university- industry-government relations in Latin América. Research Policy, v. 29, $\mathrm{n}^{\circ} 2$, p. $279-290$.

SUZIGAN et. al. (2011), Em Busca da Inovação: interação universidade-empresa no Brasil. Belo Hori- 
zonte: Editora Autêntica.

SUZIGAN, W.; ALBUQUERQUE, E. (2008), A interação entre universidades e empresas em perspectiva histórica no Brasil. Belo Horizonte: UFMG/CEDEPLAR. (Texto para discussão n. 329)

SUZIGAN, W.; ALBUQUERQUE, E. M. (2009), The underestimated role of universities for development: notes on historical roots of Brazilian System of Innovation, in: XV WORLD ECONOMIC HISTORY CONGRESS, Utrecht. Anais... Netherlands: WEHC.

TIJSSEN, R. (2006), Universities and industrially relevant science: toward mensurement models and indicators of enterpreneurial orientation. Research Police, v. 35, p. 1569-1585. 